\title{
A DRIFT IN TIME CAN DEFINE A DEME: THE IMPLICATIONS OF TRADITION DRIFT IN PRIMATE SOCIETIES FOR HOMINID EVOLUTION
}

\section{Frances D. Burton}

This material has been published in the Journal of Human Evolution 1(1):53-59. January, 1972., the only definitive repository of the content that has been certified and accepted after peer review. And is posted with permission from Elsevier Science. Copyright and all rights therein are retained by Academic Press. This material may not be copied or reposted without explicit permission. (Copyright (C) 1972 by Academic Press). IDEAL (International Digital Electronic Access Library) Reprinted with permission. http://www.elsevier.com/locate/issn/00472484 is the home page for J. Hum. Evol. Elsevier asks me to state that single copies of the article can be downloaded and printed only for the reader's personal research and study.

Primatological studies are of great interest for the information they offer on differential adaptation, by providing a broader framework for the study of human adaptation and hominization. The early assumption that a primatography of a single deme of a species could stand as a species description, has been invalidated by studies of demes of the same species which have been shown to vary in group composition and social organization. Attempts to account for the differences between -these demes has produced a vital corpus of information and allowed for the testing of theories to account for the variability. Some authorities have concentrated on the differences between demes, suggesting that social adaptations are responses to ecological variables operating on different groups. Thus, Gartlan and Brain (1968), in comparing two demes of C.aethiops stated:

"Social behavior can be seen to be a function of the interaction of the population with the environment. To the extent that both environmental requirements and the patterns comprising the normal behavior repertoire are the results of evolutionary selection, it is clear that changes in one aspect would almost inevitably involve changes in another. (1968:282)"

Other scholars have emphasized the similarities between demes, suggesting that genetic continuity between demes is more in evidence than differences. (e.g. Struhsaker, 1969), Southwick et al. (1965), studying demes of M. mulatta under different ecological conditions in north India, noted differences, but felt that "... the behavioral differences of rhesus monkeys in different habitats are basically quantitative rather than qualitative."(1965:112), an opinion shared by Jay, studying two demes of P.entellus in different areas of north India. Jay's observation that, "... variations among the different kinds of langurs are the resultsnot so much of truly diverse forms of behavior as of different degrees of emphasis on patterns of behavior common to all langurs," (1965:247) is shared by Yoshiba (1968) in his comparison of the southern form of $P$. entellus with Jay's data.

The behavioral differences between demes that have been most emphasized include presence or absence of territorial behavior, troop size and composition, adult sex ratio, tail carriage, troop movement, spatial relations between members, presence or absence of dominance hierarchy and open or closed groups. For the most part, these differences are generally interpreted as reflecting a direct behavioral response to an ecological 
54 A drift in time can define a deme

pressure, Thus, differences in sex ratio in C.aethiops have been interpreted by Gartlan and Brain as a function of the carrying capacity of the environment in which fewer males are economical in terms of diminishing food usage, while adequately fulfilling the eproductive needs of the group (1968). Troop movement differences in P. cynocephalus has been attributed to a response to decreased predation pressure (Rowell, 1969). Differences in troop size in M. mulatta has been related in part to differential stress factors (Southwick, et.al., 1965).

Where ecological pressure is not clearly seen, the exact adaptive value of a behavioral difference has been left open to question, but adaptive value is clearly assumed by most workers in the field. ${ }^{1}$

The environment of a population, however, is not responsible for the totality of its ecological fit. Every social system can be seen as a concatenation of intricate feedback circuitry which interrelates its physical setting, biological make-up or gene pool, and its traditions, behavioral pool (or behavioral repertoire). While there can be no doubt that differences in habitat present different pressures to which a group must respond, the specific nature of such responses can not be explained by this general principle. The main purpose of this paper is to offer a further factor to account for specific differences between populations.

Implicit in the works of Bernstein (1966) and Rowell (1969), and explicit in the writing of Frisch (1968) is the view that the personality of every member of a primate deme is distinct. While biological factors of age and sex are critical in influencing the behavior of the members of a troop, specific character attributes are apparent. Frisch (1968), Poirier (1970) and Burton (in press) have observed members of a troop respond to each other to a large degree in terms of individual differences rather than simply to age or sex differences. This observation permits the primatologist; to explore the extent to which an individual can influence the behavioral repertoire of its troop. Frisch (1968) has suggested that flexibility in non-hominid primate forms of social organization, seems to follow a phylogenetic continuum from Colobidae through Cercopithecidae to Pongidae. This continuum from the Prosimii to the Anthropoidea is significantly reflected in adult play behavior where the frequency of active participation in play increases phylogenetically. Alison Bishop (1964) has clearly identified play behavior as a source of behavioral evolution. She has noted that

"The tendency to play may be selected at the same time as formal intelligence, since both are required for maximum exploitation of novel situations. At the motor level, the importance of play is that the animal actively tends to vary even the patterns of control. This varying may have been a pre-adaptation to differentiate more patterns from the original ones. (1964:221)"

The expansion of the behavioral repertoire through play may afford an animal and his troop new adaptations to old or new situations.

That innovation is of importance to monkey groups has been amply illustrated by the experiments and observations at the Japan Monkey Center, especially at the colony on Koshima Island. The potato washing innovation, for example, introduced by a 16 month old female, spread through the younger animals to the older ones, reaching $50 \%$ of the troop after four years, and 71\% after nine years, and is reported by Frisch (1968)

\footnotetext{
${ }^{1}$ An illustration of this is provided by Yoshiba's study of $P$. entellus of Dharwar (1968) where leadership attainment was frequently accompanied by the killing of all the infants. This behavior is not recorded for other demes of this species, and Yoshiba felt that without further information the interpretation of this behavior was best left open.
} 
55 A drift in time can define a deme

to have reached $80 \%-90 \%$ of the troop by 1968 . The separation of grain from sand by means of water ("placer-mining") (Kawai, 1965) grew out of the earlier innovation, and Frisch reports (1968) that a refinement has emerged in which some members of the troop place themselves downstream of the current to gather the grains that have floated away. What is of major significance in these studies is that a particular member of a troop innovated a behavior unit and that the behavior acquired the characteristics of a tradition as it spread throughout the troop. As Frisch notes: "A factor that has often escaped the attention of the student of behavior in the wild ... is the different capabilites of given animals."(1968:251), Poirier has also pointed out, in discussing dominance patterns among Nilgiri langurs, that variance in such patterns ".,.is dependent upon the personalities of the animals involved, especially that of the alpha male."(1970:185), A similar phenomenon has been noted by Itani et al., in the Takasakiyama troop in the utilization of the feeding area when the leader male died and another male took over (1963), The phenomenon of a deme wide shift in behavior following an innovation ${ }^{2}$ by an individual, i.e. the fixing of a behavior unit in an existing behavior pool, is here termed tradition drift (Burton, 1972). As each member of a deme can only absorb some of the total repertoire or traditions common to its group, its acquisition and use of new behavior units will vary in form or intensity in frequency or context, from other members of the troop. Should a member of the troop through its position in the social system, exert differential influence on that troop, adoption of its innovative behavior by the troop will increase in likelihood. From the little evidence available, it seems that influence may not follow clear-cut lines of sex, age or position in any specific dominance hierarchy, and remains to be explained both in specific demes and in general.

The question arises as to whether the nature of the innovation itself may be the reason for its rapid adoption, It would seem that innovation in behavior related to such things as food habits, which are crucial in the realm of younger animals, could spread simply as a result of its apparent value. However, alterations in socialization patterns, troop movement, or social organization probably need the influence of a significant personality - in all likelihood an older animal whose position in the society is established - for widespread dissemination to occur. Indeed, speed of adoption - whatever the innovation - would seem to be related to this personality factor. An example of this was cited in the potato-washing innovation where the slow spread of the tradition seems to have been a function of the youth of the innovator. The spread of acceptance of wheat eating in the Minoo troop however, took only four hours, since the introduction and dissemination of this habit was through the agency of the leader male (Yamada, 1957).

Should the population of a troop increase beyond the carrying capacity of its environment, fission will probably occur and a behavioral founder effect might transpire. In such cases it may be argued that tradition drift could develop despite the similarity or identity of the ecological setting of the new fissioned deme, Furuya's (1969) review of fissioning in troops of $M$. fuscata is interesting in this regard, He notes that it is often not the "underprivileged" males (subleaders and ordinary males) who leave the troop, so that is virtually impossible to predict which male will become the nucleus of the new group, and therefore equally as difficult to predict the direction of drift of the behavioural repertoire.

\footnotetext{
${ }^{2}$ We use innovation to mean both the introduction of a new behavior unit and/or an increase in frequency of an existent behavior as a result of individual influence.
} 
56 A drift in time can define a deme

Mayr (1963), in discussing (genetic) founder effect notes "that:

"Since phenotypes are the product of the interaction and collaboration of many genes, it happens not infrequently that different assortments of genes may produce phenotypes that react in an identical manner to a given selection pressure, (1963:213)"

Gajdusek (1964) adds that natural selection ",, has augmented the frequency of any relatively fit array of genotypes which happened first to appear in a given population." (1964:360). An innovation in behavior, or a new emphasis on established behavior may be transmitted and become habitual if it is adaptive. Natural scientists now tend to assume adaptiveness if behavior is long-standing in a population, although the particular function or utility may not be clear to the observer (Simpson,1953). For example, the killing of the young by the new leader, reported for the Dharwar P.entellus (footnote 1), has been interpreted by Suglyama (1967) as perhaps functioning to attach the females to the male, as once their infants are gone, they come into estrus within a short period. Furthermore, "... this astonishing attack may show to the females of the troop the leader's power for organizing them without injury to themselves." (1967:233). This example may reflect merely aberrant behavior, or it may be an example of emerging tradition drift. Future study of this group will provide a proper evaluation.

The socialization process of M. sylvanus of Gibraltar ${ }^{3}$ seems also to fall into the category of emerging traditions whose adaptive function is not yet clear to the observer. The present population is descended from monkeys imported from Morocco in the early 1930's and again during World War II., which hybridized with the few then remaining monkeys. In the Middle Hill troop, the leader male was observed to take the neonate from as early as its first day of life (and not later than the fourth) for periods of from five minutes to over several hours duration. The leader male's contact with the infant appeared to include the instruction or encouragement of primary social behaviors. Among the most significant of these was the channeling (through conditioning) of the infant's basic sucking motions into the social distance-decreasing facial communication; encouraging the infant to walk after it had learned to respond to, and give this gesture, but before it has the motor coordination of its hind limbs; and reorienting the infant at the age of approximately two weeks to one month from the older animals to the younger. This reorientation was accomplished by rebuffing the sub-adult male as he attempted to bring the infant to the leader (Burton, 1972). Crook and Deag (Crook, p.c.) have studied a conspecific deme in the Moyen Atlas mountains of Morocco, where they have found that male involvement with the young is a regular aspect of behavior. Crook writes:

".... adult males in wild groups show an extraordinary amount of interest in young babies of the year .... the male Barbary Macaque does not seem, on present evidence, to limit his interest to a particular infant. He appears to appropriate babies from females in the group and to groom and care for them for short periods usually under 15 min duration. Babies may, moreover, move away from their mothers to acompany males, commonly riding off on their backs. Males carrying babies frequently approach males without them in such a way as to encourage the approached animal to engage in a mutual grooming session with the baby as target... It appears too, that most males approaching with babies are relatively juvenile animals. It looks as if relatively subordinate animals are using the babies in some way to improve their relations with higher ranking males (1970:205)."

${ }^{1}$ This material is based on field work conducted in 1970. A description of the population and anaysis of the socialization process is found in Burton (1972). 


\section{A drift in time can define a deme}

Several differences between the (single-male) Middle Hill group of M. sylvanus and the (multi-male) deme just described seem of paramount significance. In Gibraltar, the male (leader or sub-adult) regularly holds the infant for periods much exceeding 15 minutes; infants are not used to facilitate approach; infants are not used to improve the rank of the carrier; and sub-adults may carry the infant only after it is two-weeks old, while the juveniles are not permitted such contact until the infant is quite nearly two months of age. While admittedly this evidence is limited, it is important that male involvement with the young is part of the behavior pool common to both described populations, but that the intensity, duration, extent and function of the male-care behavior differs, Furthermore it is important that the adaptive significance of this Gibraltar variant in terms of direct ecological pressure is unclear. Indeed, it might be argued that the removal of the infant from its mother for extended periods of time before it is even nearing the weaning-age, is mal-adaptive, The value of the pattern, however, must be assumed because despite importation of animals from Morocco, and thus a high degree of genetic and behavioral commonalty, it exists. One possible reason is that removal from the mother seems to accelerate maturation and the value of this may be related to the presence of human beings in the Gibraltar environment. But were this true, the pattern should have existed in the neighboring Queens Gate troop, and it was not. In any case, it seems clear that the pattern has direct social significance. The extent to which the Middle Hill pattern was a function of the personality or the then leader ${ }^{4}$ male will be tested in future studies of the new leader. Having been socialized to the leader role by the former leader, his interpretation and exercise of that role in terms here particularly of infant care will help to establish the stability of this tradition as part of the behavioral repertoire of this deme.

Crook (1970) has suggested the heuristic value of studying troops of monkeys in terms of role definition and fulfillment. In this paper we have reiterated the importance of the individual in lending form to a behavioral unit or complex, The suggestion has been made that from the behavior pool common to a species, a local deme may, through the founder principle, local innovation, or the influence of individual personality, display a shift in its behavioural repertoire. Further, that this tradition drift may be adaptive in terms of the social aspects of the environment, and that direct ecological pressure may not provide necessary cause for the specific nature of such a shift. That is, behavior must, of course, be ecologically adaptive, but what appears in response to adaptive pressures can not be understood solely in terms of the physical environment.

The heuristic value of this suggestion lies not only in the possibility of extending our understanding of contemporary non-hominid primate societies, but in its application to the problem of hominization. Accepting that early hominids, like contemporary non-human primates, lived by social traditions, which with reference (of course) to the environment, permitted or provided sufficient cause for subsequent behavioral developments, the content of hominid culture may be viewed as the result of processes similar to tradition drift.

In conclusion, we are suggesting that behavioural differences between demes of the same species, can not be simply explained or understood as the result of adaptation to the selective pressures exerted by

\footnotetext{
${ }^{4}$ At the beginning of the field work in Gibraltar, the leader was a fifteen year-old male who had gained the leadership osition two years prior. This male died on September 23, 1970. By December, a four year-old male had clearly taken over the position of leader.
} 
58 A drift in time can define a deme

local ecological variations. ${ }^{5}$ We are arguing that another process (labelled here tradition drift) must be recognized for a clear understanding of such behavioral differences. This process, we suggest, is the result of two possibilities: the first of these is chance innovation, probably occurring most frequently in play behavior, and having some selective/adaptive value, which spreads and becomes fixed in the behavioral repertoire of a deme either as a result of its intrinsic value or because of the influence and personality of the innovator; the second possibility is that shifts in emphasis in the behavioral repertoire may occur as a result of fission and the founder principle. Implicitly, this means that adaptive innovations need not occur, nor if they occur, need not spread unless criteria of exposure, social structure and personality are met. This also means that different behavior, both in toto or in detail, may arise and prove adaptive for a population. If our argument is reasonable, then investigators of primate behavior should begin to consciously focus their attention on questions of deme variation in behavior. Such a focus must raise the questions of when, how, and how frequently do behavioural innovations occur, who are the innovators, what are the conditions for the spread of such innovations within a deme, how rapidly do such innovations spread, how much innovation loss occurs, when can we say that such innovations have become fixed in the behavioral pool/repertoire, etc.?

Such questions and their answers may lead us to re-examine the problem of behavioral repertoire stability in non-hominid primates. Given enough time, we may find that the behavioral repertoire may be more fluid than is now suspected. If this is the case, then our thinking on the process of hominization must be examined closely for such a state of affairs would do much to further close the behavioral gap between the non-human primates and humans especially the early hominids. It would argue for a less absolute gap between primate society and hominid culture than many have been willing to acknowledge. Moreover, if we accept the concept of tradition drift, it might provide us with a tool for the analysis of cultural content differences within the Australopithecinae (e.g. variations in apparent tool usage and production), particularly in the light of recent arguments that these hominid forms lacked symbolic vocalizations. In other words, behavioral dissemination in these forms would result from what Fried has termed "situational learning" as opposed to symbolic learning, the supposed domain of culture-bearing animals. Thus, the early hominids it may be argued, began their cultural adventure through behavioural, innovative, and accumulative processes similar to those observed among living non-human primates. Finally, we are reaffirming in this paper, the value of analogy from biological evolutionary theory to behavioral and cultural evolutionary theory when humanity is treated as a single species and cultures are treated as demes of such a species.

${ }^{5}$ On this point note our agreement with Frisch (1968:245):

"While environmental influences appear to exert at best a very limited influence on the peculiar behavioural pattern of a troop, adoption of a new type of behavior by an individual has often resulted in a durable modification in the pattern of behavior characteristic of the entire group." 
59 A drift in time can define a deme

\section{REFERENCES CITED}

Bernstein, I.S. (1966). Analysis of a key role in a capuchin (Cebus albifrons) group. Tulane Studies in Zoology. 13:49-54.

Bishop, A.(1964). Use of the hand in lower primates, In (Buettner-Janusch, Ed), Evolutionary and Genetic Biology of Primates Vol.II, Academic Press, New York. Pp.177225.

Brace, C.Loring (1967). The Stages of Human Evolution and Cultural Origins. Prentice Hall, New Jersey.

Burton, F.D. (1972). The Integration of biology and behavior in the socialization of Macaca sylvana of Gibraltar. In (F. Poirier, Ed), Primate Behavior. Random House, New York. Pp. $29-62$.

Crook, J.K.(1970). Social organization and the environment: aspects of contemporary social ethology. Animal Behaviour 18(2):197-209.

Frisch, J.E. S.J.(1968). Individual behavior and intertroop variability in Japanese macaques. In (P. Jay, Ed), Primates: studies in Adaptation and Variability. Holt, Rinehart, Winston, New York, Pp.243-252.

Fried, M. (1967). The Evolution of political society. Random House, New York.

Furuya, Y.(1969). On the fission of troops of Japanese monkeys. Primates 10:47-69.

Gajdusek, D.C. (1964). Factors governing the genetics of primitive human populations. In (N. Bleibtreu, Ed), Evolutionary Anthropology, Allyn and Bacon, Boston. 1969. Pp.347366.

Gartlan, J.S. and C.K. Brain.(1968). Ecology and social variability in C.aethiops and C. mitis. In (P. Jay, Ed) Primates: studies in adaptation and variability, Holt, Rinehart, Winston, New York. Pp.253-292.

Itani, J., K. Tokuda, Y. Furuya, K. Kano, and Y. Shin. (1963).The social construction of natural troops of Japanese monkeys in Takasakiyama. Primates 4(3):1-42.

Jay, P. (1965). The common Langur of north India, In (I. Devore, Ed). Primate Behavior: field studies of monkeys and apes. Holt, Rinehart, Winston, New York.Pp.197-249.

Kawai, M. (1965). Newly-acquired precultural behavior of the natural troops of Japanese monkeys on Koshima Islet. Primates 6(1):1-30. 
Mayr, E.(1963).Animal species and evolution. Belknap Press, Harvard.

Poirier, F. (1970) Dominance structure of the Nilgiri Langur (Presbytis johnii) of south India. Folia Primatologica 12:161-186.

Rowell, T. (1969). Long-term changes in a population of Ugandan baboons. Folia Primatologica 11:241-254.

Simpson, G.G. (1953). The Major features of evolution. Columbia University Press, New York.

Southwick, C.H., M.A. Beg, and M. Rafiq Siddiqi. (1965).Rhesus monkeys in north India. In (I. Devore, Ed) Primate behaviour: field studies of monkeys and apes. Holt, Rinehart, Winston, New York.Pp.111-159.

Strushsaker, T.T.(1969). Correlates of Ecology and social organization among African Cercopithecines: Paper prepared in advance for participation in Symposium no. 42, Social organization and subsistence in primate societies. August 19-August 28. Wenner-Gren Foundation for Anthropological Research. 1968. Summer Season.

Sugiyama, Y. (1967). Social organization of Hanuman langurs. In (S. Altman, Ed) Social communication among primates, University Chicago Press, Chicago. Pp.221-336

Yamada, M. (1957). A case of acculturation in a subhuman society of Japanese monkeys. Primates 1(1):30-46.

Yoshiba, K.(1968). Local and intertroop variability in ecology and social behavior of common Indian langurs, In (P. Jay, Ed) Primates: studies in adaptation and variability. Holt, Rinehart, Winston, New York. Pp.217-242. 